\title{
The EXCESS MICROSPOROCYTES1 gene encodes a putative leucine-rich repeat receptor protein kinase that controls somatic and reproductive cell fates in the Arabidopsis anther
}

\author{
Da-Zhong Zhao, ${ }^{1}$ Guan-Fang Wang, ${ }^{1,2}$ Brooke Speal, ${ }^{1}$ and Hong $\mathrm{Ma}^{1,2,3}$ \\ ${ }^{1}$ Department of Biology and the Life Sciences Consortium, and ${ }^{2}$ the Intercollege Graduate Program in Plant Physiology, \\ Pennsylvania State University, Pennsylvania 16802, USA
}

Cell differentiation is essential for the development of multicellular organisms. In flowering plants, the haploid male gametophytes (pollen grains) are generated in the anther from reproductive cells called microsporocytes. Several types of somatic cells ensure successful pollen development, and thus reproduction. However, it is not clear what genes regulate the differentiation of these diverse, highly specialized cells in the anther. We report here the isolation and characterization of a novel Arabidopsis thaliana male sterile mutant, excess microsporocytes1 (ems1), that produces excess microsporocytes, lacks tapetal cells, and abnormally maintains middle layer cells. Although the meiotic nuclear division in the ems1 mutant is normal, the microsporocytes do not undergo cytokinesis, resulting in failed microsporogenesis and male sterility. The EMS1 gene encodes a putative leucine-rich repeat receptor protein kinase (LRR-RPK), and its expression is associated with the differentiation of the microsporocytes and tapetal cells, suggesting that EMS1 mediates signals that control the fate of reproductive cells and their contiguous somatic cells.

[Key Words: anther; Arabidopsis; cell fate; leucine-rich repeat receptor protein kinase; male sterility; reproductive and somatic cells]

Received April 10, 2002; revised version accepted May 31, 2002.

The life cycle of flowering plants alternates between the diploid sporophyte and haploid gametophyte generations. Male gametophytes develop in anthers where cell division, differentiation, and subsequent degeneration are essential for successful reproduction (Scott et al. 1991; Goldberg et al. 1993; McCormick 1993). The anther usually has a four-lobed structure consisting of highly specialized reproductive and nonreproductive tissues (Goldberg et al. 1993). The reproductive tissue contains microsporocytes that undergo meiosis and produce microspores that in turn develop into pollen grains. The nonreproductive tissues or somatic cell layers, including the epidermis, endothecium, middle layer, and tapetum, are required for normal pollen development and the release of pollen grains. In particular, the importance of tapetum for pollen development has been demonstrated by the observation that selective destruction of the tapetum in tobacco and oilseed rape results in the failure of

${ }^{3}$ Corresponding author.

E-MAIL hxm16@psu.edu; FAX (814) 863-1357.

Article and publication are at http://www.genesdev.org/cgi/doi/10.1101/ gad.997902. pollen formation (Mariani et al. 1990, 1992; Denis et al. 1993). Therefore, the anther offers an excellent system to study cell type differentiation and cell signaling in the plant.

The ontogeny of the anther is divided into two phases (Goldberg et al. 1993). During the first phase, anther morphology is established and the differentiation of multiple and highly specialized types of cells is completed. In particular, archesporial cells give rise to the microsporocytes, tapetum, middle layer, and endothecium. In addition, microsporocytes undergo meiosis toward the end of this phase. In the second phase, the anther enlarges in size and microspores develop into pollen grains. Subsequently, specific anther tissues degenerate and the anther dehisces to release the pollen grains. Genetic and molecular studies have revealed that the identity of stamen primordium is controlled by the combination of class B and C genes in Arabidopsis, snapdragon, and a number of other plants (Coen and Meyerowitz 1991; Meyerowitz et al. 1991; Ma 1994; Weigel 1995; Ma and dePamphilis 2000). In Arabidopsis, the B genes APETALA3 and PISTILLATA (Bowman et al. 1989; Jack et al. 1992; Goto and Meyerowitz 1994), the C 
gene AGAMOUS (Yanofsky et al. 1990), and the SEPALLATA1/2/3 genes (Pelaz et al. 2000) are required for normal anther initiation. However, it is unknown how these genes control cell fate determination in the stamen.

The Arabidopsis mutant sporocyteless (spl) (Yang et al. 1999), which is allelic with nozzle (nzz) mutants (Schiefthaler et al. 1999; Balasubramanian and Schneitz 2000), fails to form both male and female sporocytes. SPL $(N Z Z)$ encodes a novel nuclear protein and is expressed before the initial archesporial periclinal cell divisions in the anther, suggesting that $S P L(N Z Z)$ plays an early role in the anther development. During later stages of anther development, several Arabidopsis mutants have been found to exhibit defects in tapetum development. For example, in the ms9 and ms15 mutants, the tapetum degenerates prematurely (Taylor et al. 1998). In addition, the ms1 mutation causes tapetal cells to become abnormally vacuolated after the microspores are released from the tetrads; the MS1 gene encodes a putative transcriptional regulator with a PHD-finger motif (Dawson et al. 1993; Wilson et al. 2001). Also, the tapetum and middle layer in the fat tapetum mutant enlarge beyond their normal sizes with concurrent breakage and degeneration of microspores (Sanders et al. 1999). However, very little is known about the molecular mechanisms controlling cell fate determination, cell patterning and cell signaling in the anther. Specifically, genes controlling the tapetal cell identity have not yet been described.

Here we describe the isolation and analysis of a novel Arabidopsis male sterile mutant, excess microsporocytes1 (ems1). In addition to producing excess microsporocytes, the ems 1 mutant lacks tapetal cells, and maintains the middle layer for a period of time longer than wild-type plants. The male meiotic nuclear division seems normal in the ems 1 mutant, but the male meiotic cytokinesis does not occur, resulting in the failure of microsporogenesis and male sterility. The EMS1 gene was isolated by transposon tagging, and it encodes a putative leucine-rich repeat receptor protein kinase (LRRRPK). Furthermore, EMS1 expression is associated with the differentiation of the microsporocytes and tapetal cells, thereby suggesting that EMS1 controls the fate of reproductive cells and their adjacent somatic cells.

\section{Results}

\section{Isolation of the excess microsporocytes 1 mutant}

To identify genes that are important for the regulation of anther development, we generated Arabidopsis insertion lines using a transposon derived from the maize $D s$ element (Sundaresan et al. 1995). After screening 359 Ds insertion lines, we found one line that segregated for male sterile plants. The F1 plants from a cross between the sterile mutant and the wild type had normal fertility, and the F2 plants segregated for both normal fertility $(98$ plants) and sterility ( 31 plants), indicating that the defect was likely caused by a recessive mutation in a single gene. The $D s$ element carries the $\mathrm{Kan}^{\mathrm{R}}$ marker, allowing the presence of the $D s$ element to be determined using a plate assay. Approximately three-quarters (128) of the F3 seedlings from $D s /-$ F2 plants were kanamycin-resistant, and one-quarter (44) were kanamycin-sensitive. In addition, when the kanamycin-resistant seedlings were grown to maturity, one-third (41) displayed the sterility phenotype. These results suggest that the male sterile mutation may be linked to the $D s$ insertion.

\section{Phenotypic analysis of the excess microsporocytes 1 mutant}

Although the newly isolated mutant was completely male sterile, it exhibited normal vegetative and floral development (Fig. 1A,B,D,E). To analyze the developmental defects that caused male sterility in the mutant, we compared anther and pollen development in wildtype and mutant plants. The wild-type mature and immature anthers contained pollen grains and microspores, respectively (Fig. 1G,I), but the mutant anthers lacked pollen grains and microspores (Fig. $1 \mathrm{H}, \mathrm{J})$.

We then prepared transverse sections of anthers to further examine defects in the mutant. Anther development in Arabidopsis has been divided into 14 stages based on morphological landmarks of cellular events visible under the light microscope (Sanders et al. 1999). From stage 1 to 4 , a four-lobed structure is generated. A stage-1 anther has L1, L2, and L3 layers. The L1 layer provides cells for the epidermis, and the L2 layer is largely responsible for generating cells for other somatic layers and the sporogenous tissue in each lobe. The L3 layer forms the vascular and other tissues at the center of the anther. Archesporial cells are derived from the L2 layer at stage 2 , and then divide to form primary sporogenous cells and primary parietal cells at stage 3 . The primary sporogenous cells will divide and develop into microsporocytes, whereas the primary parietal cells further divide into two sets of secondary parietal cells. At stage 4 , the inner set of secondary parietal cells adjacent to the sporogenous cells divide and differentiate into tapetal cells, and the secondary parietal cells in the outer set divide again to form endothecium and the middle layer. At this time, the cells of endothecium, middle layer, and precursors of the tapetal cells are not yet organized into layers, because they are not formed synchronously (Fig. 2A). There was no detectable difference between a wild-type and mutant anther from stage 1 to 3 (data not shown). At stage 4, the structure of the mutant anther resembled that of the wild-type anther; however, it is not known whether all of the cells are identical between the wild-type and the mutant (Fig. 2A,B).

During stage 5 in a wild-type anther, microsporocytes are formed at the center of each lobe (Fig. 2C,E). At this point, five cell layers can be recognized; they are, from outside to inside, the epidermis, endothecium, middle layer, tapetum, and microsporocytes. The microsporocytes are typically larger than the tapetal cells, which are close to rectangular in shape and have formed a clearly recognizable layer interior to the thin middle layer (Fig. $2 \mathrm{E})$. In contrast, the mutant anthers at early stage 5 had no tapetal layer (Fig. 2D) and at late stage 5 they had 

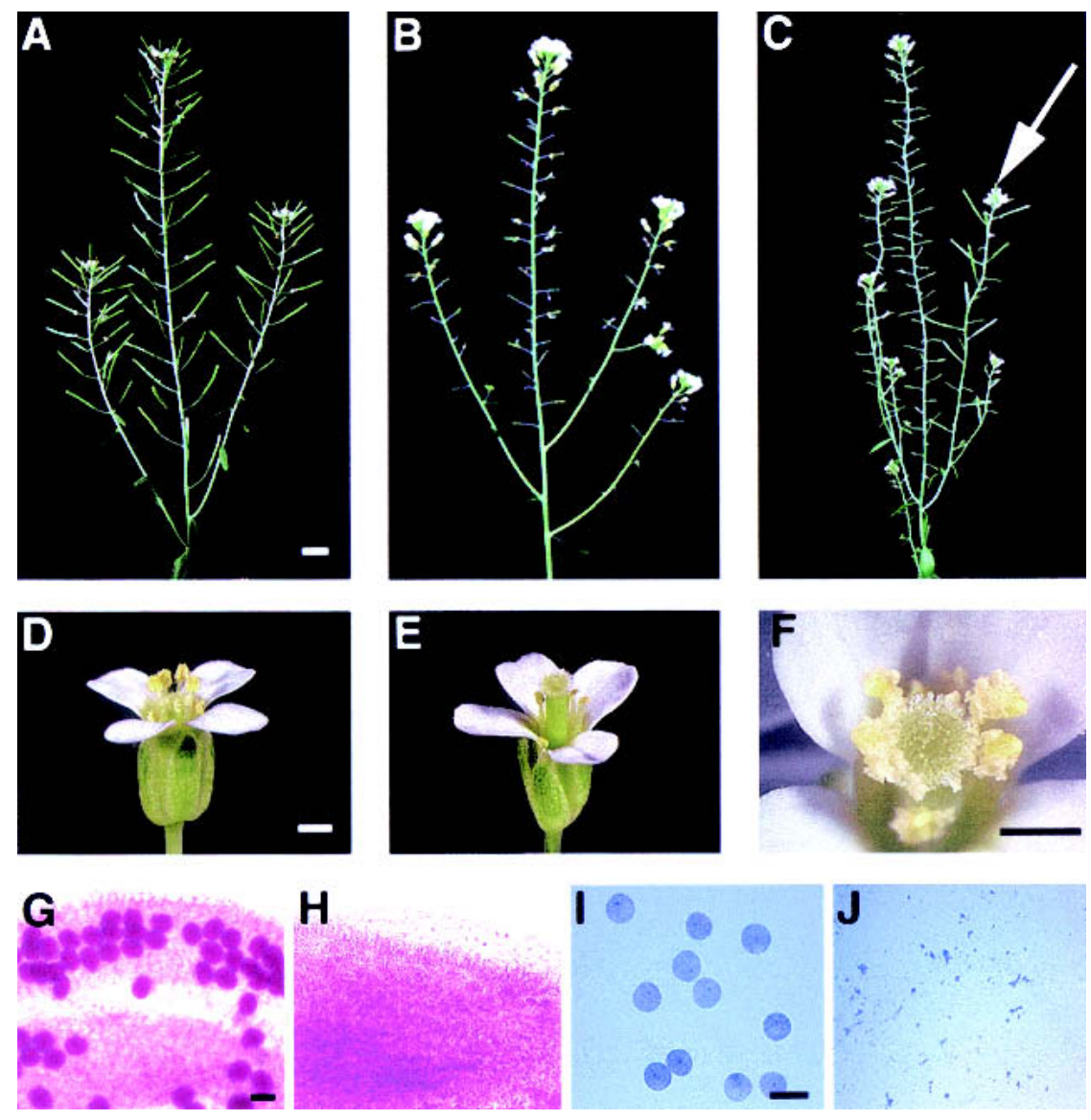

Figure 1. Comparison of the wild-type, ems1 mutant, and revertant plants and flowers. (A) A wild-type plant showing normal seedpods. (B) A mutant plant with small seedpods with no developing seeds. (C) A mutant plant with revertant sectors showing large seedpods (arrow). (D) A wildtype flower showing pollen grains. $(E) \mathrm{A}$ mutant flower lacking pollen grains. $(F)$ A close-up view of a revertant flower showing pollen grains. $(G)$ A portion of wild-type anther with functional pollen grains stained in red. $(H)$ A portion of ems1 mutant anther without pollen grains. (I) Microspores from wild-type anther regular in size. (J) Debris from ems1 mutant anther at stage similar to that shown in $I$. In $A$, bar, $5 \mathrm{~mm}$. In $D, F$, bar, $500 \mu \mathrm{m}$. In $G, I$, bar, $10 \mu \mathrm{m}$. $A-C$; $D$ and $E ; G$ and $H_{;} I$ and $I$ have same magnification. excess microsporocytes (Fig. 2F). Therefore, we named the mutant excess microsporocytes 1 (ems1). At stage 6, the microsporocytes in the wild-type anther are detached from the tapetum and each other (Fig. 2G). The tapetal layer is very distinctive, with vacuolated and intensely stained cells (Fig. 2G). In addition, the middle layer degenerates and collapses to a thin line (Fig. 2G). However, in stage- 6 ems 1 anthers, the microsporocytes still adhered to each other and were abnormally enlarged (Fig. $2 \mathrm{H})$. Furthermore, the middle layer was still visible in the mutant anther (Fig. 2H).

In stage-7 wild-type anthers, meiotic cytokinesis has completed, resulting in the formation of tetrads in the anther locule (Fig. 2I). In contrast, the ems1 anthers lacked tetrads (Fig. 2J); instead the microsporocytes had degenerated, suggesting that microsporogenesis was arrested prior to meiotic cytokinesis. Moreover, the mutant middle layer continued to persist (Fig. 2J). In the wild type, at stage 8 , the callose wall of tetrads degenerates and individual microspores are released (data not shown). At stage 9, the microspores become vacuolated and the exine wall is formed (Fig. 2K). During stages 7 to 9 , the tapetal layer still exists in the wild type (Fig. 2I,K). However, in the mutant, the undivided microsporocytes in the locule disintegrated into cell fragments or debris and the middle layer was still present (Fig. 2J,L; data not shown). In the wild type, tapetum degeneration initiates at stage 10 and is completed at stage 12 (data not shown).
From stage 12 to 15 , dehiscence occurs and pollen grains are released. In the mutant, locules eventually became empty (data not shown). During dehiscence, the anther wall broke open, although no pollen grains were there to be released.

We observed that in the ems1 mutant, the formation of archesporial cells, primary sporogenous cells, primary parietal cells, and secondary parietal cells was normal, indicating that cell division in the first anther phase was not affected. However, excess microsporocytes were formed. The tapetal cells were absent, and the middle layer persisted beyond the normal stage of its presence. These results indicate that the EMS1 gene is required for normal cell differentiation in anther development.

\section{The excess microsporocytes 1 mutant is defective in controlling cell fate in anther development}

The phenotypic analysis described above suggests that in the ems 1 mutant, cells from the inner secondary parietal cells developed into excess microsporocytes. If this is true, the number of microsporocytes in the ems 1 mutant anther should be close to the sums of the numbers of normal microsporocytes and tapetal cells. We examined 160 locules of wild-type and ems1 anthers (see Materials and Methods), and found that the number (with standard deviation) of microsporocytes in sections of a mutant locule near the middle of the anther $(16.0 \pm 0.4)$ was 
Zhao et al.

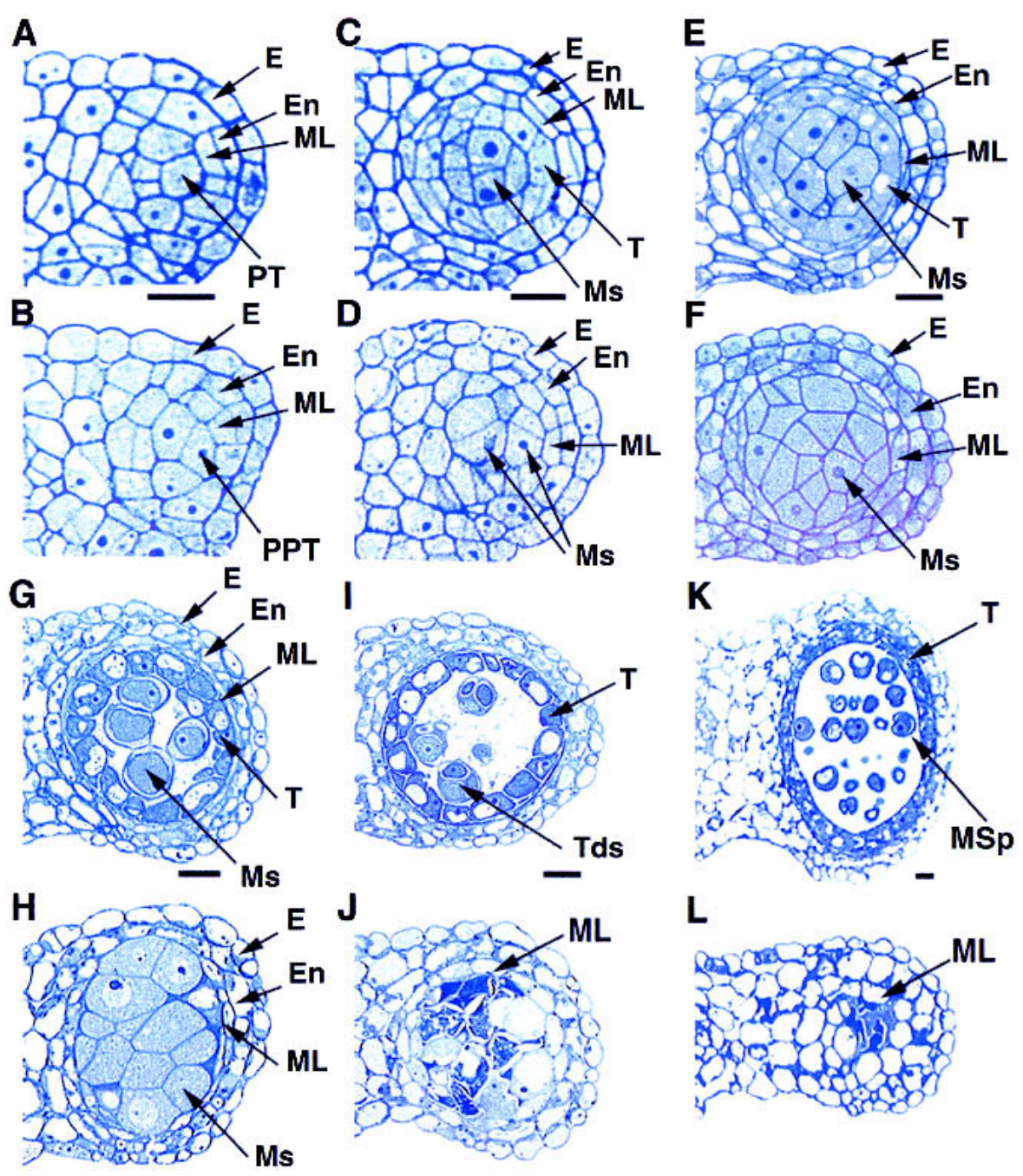

Figure 2. Comparison of the wild-type and ems1 mutant anther development. The panels show the upper right lobe of the anther. $(A)$ Wild-type anther at stage 4 with the epidermis, endothecium, middle layer, and precursors of tapetal cells; cells of a particular layer are not formed simultaneously. $(B)$ Stage-4 mutant anther with a structure similar to the wild-type in $A$. $(C)$ Wild-type anther at early stage 5 showing the epidermis, endothecium, middle layer, tapetal layer, and microsporocytes. $(D)$ Mutant anther at early stage 5 lacking the tapetal layer. $(E)$ Wild-type anther at late stage 5 with structure similar to that in $C$. $(F)$ Mutant anther at late stage 5 with excess microsporocytes and a more obvious absence of the tapetal layer. $(G)$ Stage- 6 wild-type anther with epidermis, endothecium, degenerated middle layer, vacuolated tapetal cells, and isolated microsporocytes. $(H)$ Mutant anther at stage 6 containing enlarged and undetached microsporocytes. The middle layer had not degenerated. $(I)$ Stage-7 wild-type anther showing tapetal layer and tetrads. $(J)$ Stage-7 mutant anther with degenerating microsporocytes and lacking tapetal layer. The middle layer was still present. (K) Wild-type anther at stage 9 with tapetal layer and microspores. $(L)$ Stage- 9 mutant anther showing degenerated microsporocytes and persistent middle layer. E, epidermis; En, endothecium; ML, middle layer; Ms, microsporocytes; MSp, microspores; PT, precursors of tapetal cells; PPT, putative precursors of tapetal cells; T, tapetal layer; Tds, tetrads. Bar, $10 \mu \mathrm{m}$. $A$ and $B, C$ and $D, E$ and $F, G$ and $H, I$ and $J, K$ and $L$ have same magnification.

much greater than that of the wild-type $(5.3 \pm 0.2)$, but close to the sum of microsporocytes and tapetal cells in the wild type $(18.5 \pm 0.4)$. This is consistent with the idea that, in the ems 1 mutant, the cells that normally develop into tapetal cells had differentiated into microsporocytes, apparently without alteration in cell division.

Although the microsporocytes appeared normal initially, they become abnormal subsequently and eventually degenerated. Since it was not clear whether meiotic nuclear division occurred in these microsporocytes, we examined meiosis in the mutant and compared that with the wild type. Wild-type microsporocytes undergo meiosis at stage-6 anther (Fig. 3A,C,E). In ems1 microsporocytes, meiotic nuclear division seemed to occur normally (Fig. 3B). We examined 1258 microsporocytes from the ems 1 mutant, and found various stages of meiotic nuclear division, from prophase I to telophase II (e.g., Fig. $3 \mathrm{D}, \mathrm{F})$, suggesting that the meiotic nuclear division was normal in the ems1 mutant. 

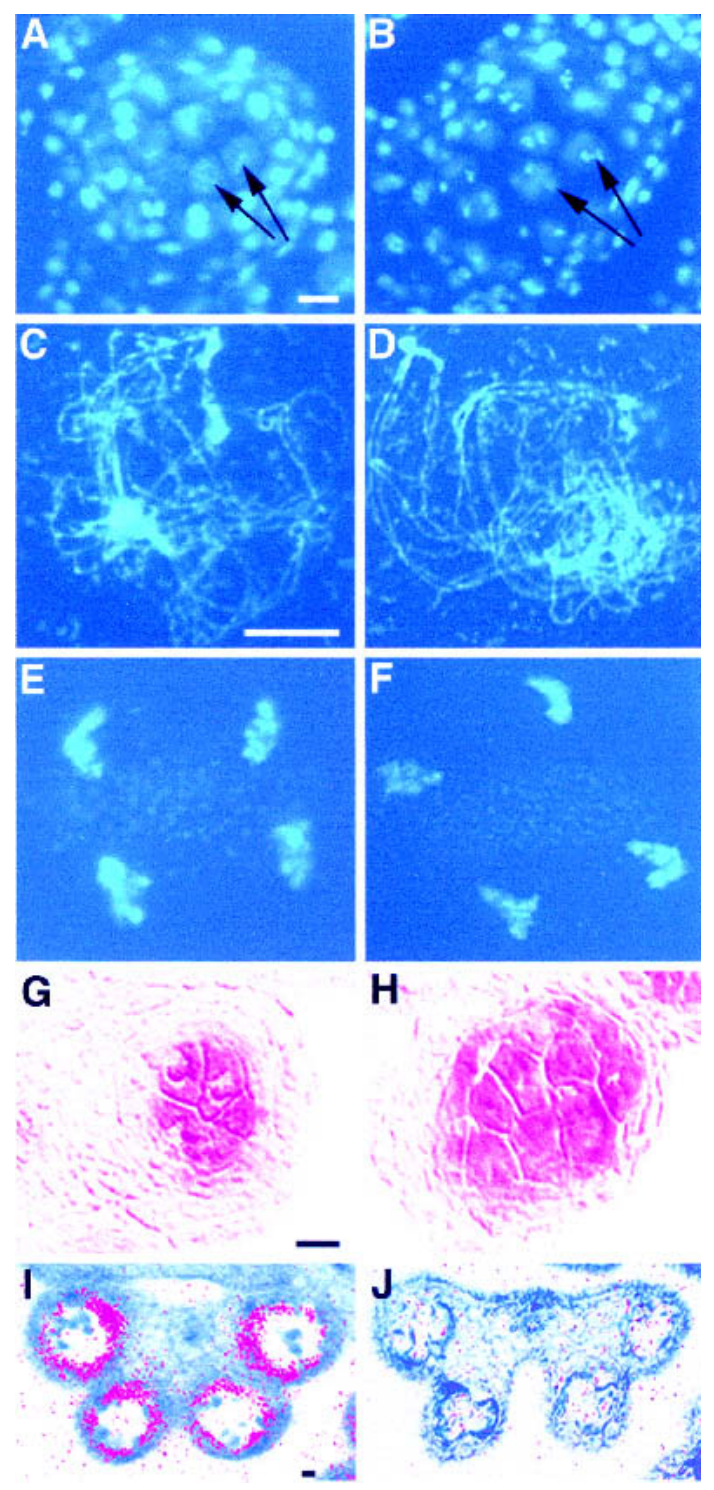

Figure 3. The ems1 mutant produces excess microsporocytes but has no tapetal cells. (A) DAPI staining of the wild-type section indicating that microsporocytes are undergoing meiosis (e.g., arrows). (B) DAPI staining of the mutant section showing that all microsporocytes (e.g., arrows) were undergoing meiosis. $(C-F)$ DAPI-stained spread chromosomes. (C) Wild-type prophase I at zygotene. $(D)$ Mutant prophase I at zygotene. $(E)$ Wildtype telophase II. (F) Mutant telophase II. $(G)$ The meiosis-specific gene $S D S$ was expressed in wild-type microsporocytes. $(H)$ $S D S$ was expressed in all microsporocytes in the mutant. (I) A stage- 8 wild-type anther exhibiting tapetum-specific expression of the ATA7 gene. (J) A stage-8 mutant anther without ATA7 expression. Bar, $10 \mu \mathrm{m}$. $A$ and $B, C-F, G$ and $H, I$ and $J$ have same magnification.

To confirm the identity of the excess microsporocytes in the ems1 mutant, we tested the expression of the SDS gene, which is specifically expressed in the microsporocyte (Azumi et al. 2002). As shown in Figure 3G, SDS is expressed only in the microsporocytes of a wild-type anther. In the ems1 mutant, $S D S$ was expressed in the mi- crosporocytes that occupied normal positions and in the surrounding excess microsporocytes, supporting the idea that these cells were indeed microsporocytes (Fig. 3H). Furthermore, to verify the lack of tapetum in the ems 1 mutant, we examined the expression of the ATA7 gene, the earliest available tapetum-specific molecular marker (Rubinelli et al. 1998). Whereas ATA7 is clearly expressed in the wild-type anther (Fig. 3I), its expression could not be detected in an ems1 anther, providing molecular evidence for the absence of tapetal cells (Fig. 3J).

Therefore, analyses using cytological and molecular markers all indicate that excess microsporocytes were formed in the ems 1 mutant at the expense of tapetal cells. Cell numbers in mutant and wild-type anthers support the idea that the ems 1 mutation causes the differentiation of cells derived from the inner secondary parietal cells into excess microsporocytes.

\section{Isolation of the EMS1 gene}

The ems1 mutant carried a single $D$ s insertion, as supported by cosegregation of the $D s$ with the mutant phenotype and by the recovery of several large fertile revertant sectors from mutant plants carrying an $A c$ element (e.g., Fig. 1C,F). Thermal asymmetric interlaced-PCR (TAIL-PCR; Liu et al. 1995) was used to obtain the plant sequences adjacent to both ends of the Ds element (data not shown). The sequences of these TAIL-PCR products revealed that the $D s$ element was inserted four codons downstream of the ATG codon of a predicted open reading frame (ORF; Protein ID CAB87284) with a typical 8-bp duplication (Fig. 4A). Analysis of the insertion site of two revertant plants identified 6-bp and 9-bp insertions, respectively, which did not disrupt the ORF, clearly demonstrating that the $D s$ insertion was responsible for the male sterility phenotype (Fig. 4A). The predicted EMS1 gene (At5g07280) in the Arabidopsis genomic sequence lacks any intron, and there was no EST for this gene. To verify the exon-intron structure, we amplified an EMS1 cDNA containing the entire protein coding region; its sequence confirmed the predicted intronless gene structure and has been submitted to GenBank (accession no. AJ488154).

\section{The EMS1 gene encodes a putative LRR-RPK}

The EMS1 gene encodes a putative LRR-RPK of 1192 amino acids with three major domains: an N-terminal extracellular receptor-like domain with 30 LRRs, a predicted transmembrane domain, and a cytoplasmic protein kinase domain (Fig. 4B,C). A BLASTP search was performed using the entire amino acid sequence of the predicted EMS1 protein and indicated that there are several proteins in Arabidopsis with $\sim 30 \%$ amino acid sequence identity to EMS1. Specifically, EMS1 has 33\% (317/960) identity and 48\% (468/960) similarity to ERECTA (U47029), and 32\% (316/970) identity and 47\% (470/970) similarity to CLV1 (U96879). In addition, a predicted Arabidopsis LRR-RPK (NP-193747.1) has the 


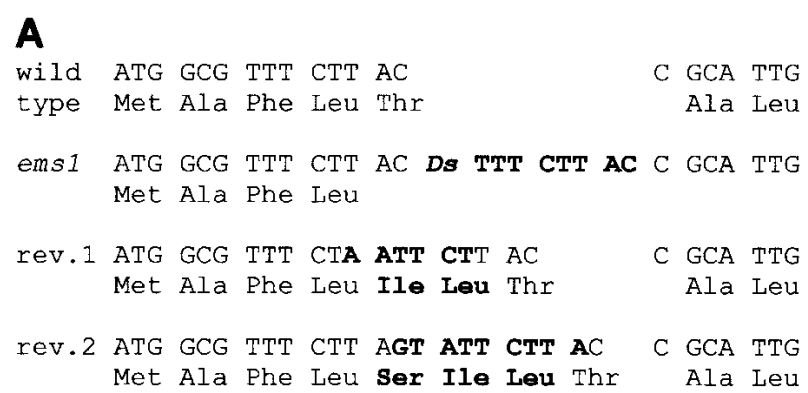

B

MAFLTALFLFLFFSFSSSAIVDLSSETTSLISFKRSLENPSLLSSWNVSS 50 SASHCDWVGVTCLLGRVNSLSLPSLSLRGQI PKE ISSIKNLRELCLAGNQ 100 FSGKI PPE I WNLKHLQTLDLSGNSLTGLLPRLLSELPQLLYLDLSDNHFS 150 GSIPPSFFISLPALSSLDVSNNSLSGE IPPEIGKLSNLSNLYMGLNSFSG 200 QIPSEIGNISLLKNFAAPSCFFNGPLPKEISKLKHLAKLDLSYNPLKCSI 250 PKSFGELHNLS ILNLVSAELIGLIPPELGNCKSLKSLMLSFNSLSGPLPL 300 ELSE I PLLT FSAERNOLSGSLPSWMGKWKVLDSLLLANNRFSGEIPHE IE 350 DCPMLKHLSLASNLLSGSIPRELCGSGSLEAIDLSGNLISGTIEEVFDGC 400 SSLGELLLTNNQINGS I PEDLWKL PLMALDLDSNNFTGEIPKSLWKSTNL 450 MEFTASYNRLEGYLPAEIGNAASIKRLVLSDNQLTGEIPREIGKLTSLSV 500 LNLNANMFQGKIPVELGDCTSLTTLDLGSNNLOGQI PDKITALAQLQCLV 550 LSYNNLSGS IPSKPSAYFHQIEMPDLSFLQHHGI FDLSYNRLSGPI PEEL 600 GECLVLVEISLSNNHLSGEIPAS LSRLTNLTIIDLSGNALTGSI PKEMGN 650 SLKLQGLNLANNQLNGHIPES FGLLGSLVKLNITKNKLDGPVPASIGGNLK 700 ELTHMDLSFNNLSGELSSELSTMEKLVGLYIEQNKETGEI PSELGNLTQL 750 EYLDVSENLLSGEI PTKICGLPNLEFLNLAKNNLRGEVPSDGVCQDPSKA 800 LLSGNKELCGRVVGSDCKIEGTKLRSAWGIAGLMLG F"TIIVFVFVESLRR 850 WAMTKRVKQRDDPERMEESRLKGFVDQNLYFLSGSRSREPLS INIAMFEQ 900 PLLKVRLGDIVEATDHFSKKNI IGDGGEGTVYKACLPGEKTVAVKKLSEA 950 KTOGNRE FMAEMETI.GKVKHPNLVSLLGYCSFSEERLLVYEYMVNGSLDH 1000 WLRNQTGMLEVLDWSKRLKIAVGAARGLAFLHHGEIPHIIHRDIKASNIL 1050 LDGDFE PKVADFGLARLISACE SHVSTVIAGT FGYIPPEYGQSARATTKG 1100 DVYS FGVILLELVTGKE PTGPDFKESEGGNLVGWAIQKINQGKAVDVIDP 1150 LLVSVALKNSQLRLIQIAMLCLAET PAKRPNMLDVLKALKEI 1192

C

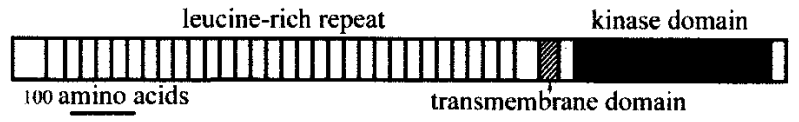

Figure 4. Molecular characterization of the EMS1 gene. (A) The mutant sequence has an 8-bp duplication and the revertants (rev.) show 6- and 9-bp insertions, respectively (in boldface). (B) The EMS1 protein sequence. $(C)$ A diagram of EMS1 protein shows LRRs, transmembrane domain, and kinase domain.

highest similarity to EMS1 with $33 \%$ identity over most of the sequence ( $49 \%$ similarity). In all of these cases, the similarity between kinase domains is higher than that between LRR domains (data not shown).

To determine whether EMS1 possesses a protein kinase activity, we produced a fusion protein between glutathione S-transferase (GST) and the EMS1 kinase domain using heterologous expression in Saccharomyces cerevisae (Skirpan et al. 2001). We found that the purified recombinant protein exhibited an autophosphorylation activity when incubated with $\left[\gamma^{-32} \mathrm{P}\right]$ ATP (Fig. 5A), suggesting that EMS1 is indeed a protein kinase. If EMS1 is also a receptor, it should localize to the plasma membrane. To test the localization of EMS1, we constructed a translation fusion between a new synthetic green fluorescent protein (sGFP; Chiu et al. 1996) and the EMS1 fragment with the predicted transmembrane domain region and a portion of the kinase domain. The EMS1-GFP fusion and GFP alone, both driven by the $35 \mathrm{~S}$ promoter,
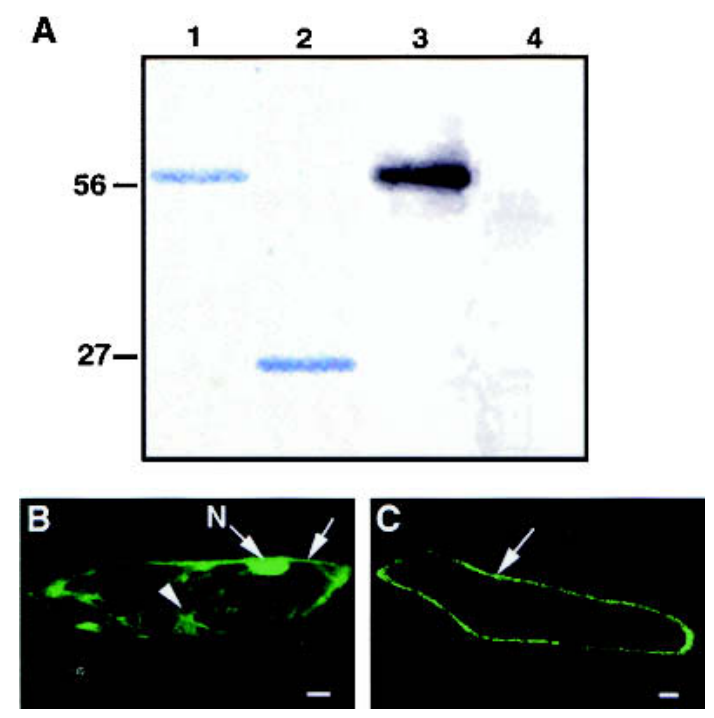

Figure 5. Kinase activity analysis of the EMS1 protein and subcellular localization of an EMS1-GFP fusion protein. (A) Autophosphorylation activity of the EMS1 kinase domain. (Lane 1) A fusion protein between the EMS1 kinase domain and GST. (Lane 2) GST protein. (Lane 3) The fusion protein between the EMS1 kinase domain and GST showing kinase activity of autophosphorylation. (Lane 4) GST alone having no activity of autophosphorylation. (B) A cell that expressed free GFP showing fluorescence in nucleus (N), cytoplasm (arrowhead), and plasma membrane (arrow). (C) A cell that expressed EMS1-GFP showing fluorescence in the plasma membrane (arrow). Bar, $25 \mu \mathrm{m}$.

were introduced into onion epidermal cells by particle bombardment. As expected, the free GFP was expressed strongly in the nucleoplasm, as well as in the cytoplasm and the plasma membrane (Fig. 5B). In contrast, the EMS1-GFP fusion protein was observed at the cell periphery as a thin line (Fig. $5 \mathrm{C}$ ), suggesting that EMS1GFP localized to the plasma membrane.

\section{Expression of the EMS1 gene}

To gain further insight into the action of the EMS1 gene, we analyzed its expression pattern using in situ RNA hybridization experiments. The EMS1 gene was only expressed in the anthers of young floral buds (data not shown). The expression of the EMS1 gene was first detected in archesporial cells in stage-2 anthers (Fig. 6A), and then in both sporogenous and parietal cells at stage 3 (Fig. 6B). The EMS1 mRNA was predominately detected in sporogenous and parietal cells at stage 4 (Fig. $6 \mathrm{C})$. At stage 5, the EMS1 gene was expressed more strongly in the tapetum than in the microsporocytes (Fig. 6D). The EMS1 transcript level was reduced greatly in both tapetum and microsporocytes at stage 6 (Fig. 6E). The EMS1 gene expression was reduced gradually from stage 6 and was not detectable at about stage 9 (data not shown). As a control, only background levels of signal were detected when a sense probe was used for hybridization (Fig. 6F). Therefore, our results strongly indicated 


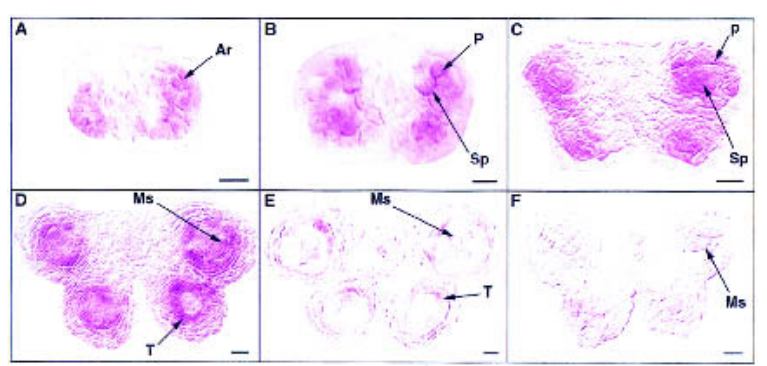

Figure 6. The EMS1 gene expression pattern. (A) A wild-type anther at stage 2 showing that the EMS1 gene was expressed in archesporial cells. $(B)$ A stage-3 wild-type anther indicating that EMS1 was expressed in the four corners of anther with sporogenous and parietal cells. (C) A stage- 4 wild-type anther showing that $E M S 1$ was predominately expressed in both sporogenous and parietal cells. $(D)$ A wild-type anther at stage 5 showing that EMS1 was strongly expressed in the tapetal layer but less in microsporocytes. (E) A stage-6 wild-type anther showing that EMS1 expression was greatly reduced. $(F)$ A wild-type anther at early stage 5 with sense probe lacking a specific signal. Ar, archesporial cells; Ms, microsporocytes; P, parietal cells, Sp, sporogenous cells; $\mathrm{T}$, tapetal layer. Bar, $10 \mu \mathrm{m}$.

that the EMS1 expression is associated with the differentiation of microsporocytes and tapetal cells.

\section{Discussion}

The EMS1 gene regulates anther cell development in Arabidopsis

We report here the characterization of the EMS1 gene in Arabidopsis. Based on morphological studies, cell division during early anther development is normal in the ems1 mutant. On the other hand, the ems1 mutant had excess microsporocytes but no tapetal layer, suggesting that the cells derived from the inner secondary parietal cells differentiated into additional microsporocytes. The statistical results indicated that the number of microsporocytes formed in the mutant is close to the sum of the number of microsporocytes and tapetal cells in the wild type. Furthermore, the meiotic nuclear division in the ems1 mutant is normal, but the microsporocyte cytokinesis is arrested, resulting in the failure of microsporogenesis and male sterility. In addition, the structure of the middle layer cell abnormally persists. Taken together, these findings indicate that the EMS1 gene regulates anther cell development, particularly the cell differentiation. Our observation that EMS1 is expressed in microsporocytes and other cells before and during tapetum differentiation strongly suggests that EMS1 is not sufficient for specifying the tapetal cell fate.

Somatic cells are very important for male reproduction; their functions include providing substances for pollen development and releasing matured pollen grains. The tapetum is thought to nourish the developing pollen (Pacini et al. 1984; Scott et al. 1991; Goldberg et al. 1993). On the basis of cytological and histochemical studies, several functions of the tapetum in supporting pollen development have been proposed. First, the tapetum produces and releases callase and some other proteins and enzymes, which are important for the release of microspores from the tetrad (Mepham 1970; Izhar and Frankel 1971; Stieglitz 1977). In addition, tapetum cells secrete starch-containing substances into the locule (Gori 1982; Pacini and Juniper 1983). The tapetum also provides molecules for the formation of the pollen outer wall called exine and tryphine, a proteinaceous coating of pollen. The importance of the tapetum is supported by the observation that selectively destroying the tapetum causes the failure of pollen formation in tobacco and oilseed rape (Mariani et al. 1990, 1992; Denis et al. 1993). This idea is further supported by the finding that mutants that are defective in tapetum development also produce abnormal microsporocytes or pollen grains. For example, in the ms3 mutant, tapetal cells and middle layers become vacuolated and markedly enlarged, and microsporocytes are irregularly shaped (Chaudhury et al. 1994). It is known that microspores are capable of continued development in vitro, suggesting that postmeiotic tapetum might function mainly in provision of substances (Takegami et al. 1981).

Although tapetal cells support pollen development, it is not known whether the tapetum affects male meiosis. Among previously described Arabidopsis mutants with tapetum defects, the $s p l$ (nzz) mutant lacks both the tapetum and microsporocytes (Schiefthaler et al. 1999; Yang et al. 1999; Balasubramanian and Schneitz 2000), and other mutations cause the abnormal tapetum development but not the lack of the tapetum (Dawson et al. 1993; Chaudhury et al. 1994; Taylor et al. 1998; Sanders et al. 1999). In the ems1 mutant, the tapetum is completely absent, but meiotic nuclear division still occurs, suggesting that tapetal cells are not critical for meiotic nuclear division. On the other hand, the ems1 microsporocytes failed to undergo cytokinesis, indicating that EMS1 is required for normal meiotic cytokinesis. One possibility is that tapetal cells are required for meiotic cytokinesis and spore formation. Alternatively, the EMS1 gene may act in microsporocytes to promote meiotic cytokinesis. In either case, the observation that EMS1 expression was detected in both the sporogenous cells and parietal cells suggests that the formation of the microsporocyte layer and that of the somatic cell layer are coupled.

The spl (nzz) mutant phenotype and the SPL (NZZ) expression pattern suggest that $S P L(N Z Z)$ regulates the formation of anther primordium very early in anther development (Schiefthaler et al. 1999; Yang et al. 1999; Balasubramanian and Schneitz 2000). The ems1 mutant can normally produce precursors of different types of cells, indicating that the EMS1 gene is not required for those early events. The failure of the ems1 mutant to form the tapetum and the presence of excess microsporocytes indicate that the EMS1 gene controls cell fates subsequent to the time of $S P L$ (NZZ) function. Furthermore, the fact that microsporocytes are formed instead of tapetal cells in the ems 1 mutant indicates that the fate 
of microsporocytes is controlled by a default pathway and that tapetal cell fate requires an additional pathway that is dependent on the EMS1 gene.

\section{The EMS1 gene is involved in a new signal pathway} to regulate the cell fate in plant

Receptor protein kinases (RPKs) are a diverse group of proteins that are key components of signal transduction pathways in both animals and plants (Becraft 1998; Schenk and Snaar-Jagalska 1999). RPKs usually consist of three domains: a large extracellular domain, a single transmembrane domain, and a cytoplasmic domain of protein kinase (Walker 1994; Stone and Walker 1995). At least 610 Arabidopsis genes have been found to encode RPKs; they represent nearly $2.5 \%$ of total protein coding genes in the Arabidopsis genome (Shiu and Bleecker 2001). Five major RPK families are recognized in plants according to the structures of their putative ligand-binding domains (McCarty and Chory 2000): LRR-RPK family, S-domain RPK family, CR4-like RPKs, lectin-type RPK family, and wall-associated kinases (WAKs).

Leucine-rich repeat receptor protein kinases (LRRRPKs) make up the largest family of plant RPKs, with over 200 predicted members in Arabidopsis, of which only a few have known biological functions (McCarty and Chory 2000; http://www.wisc.edu/prkr//. Both CLV1 and ERECTA are important for normal Arabidopsis development: $C L V 1$ controlling cell division and cell differentiation in the shoot apical meristem (Clark et al. 1996, 1997) and ERECTA regulating stem and fruit elongation and other processes (Torii et al. 1996). The HAESA gene regulates the differentiation of the abscission zone of floral organs (Jinn et al. 2000). Also, the petunia PRK1 protein is important for pollen development (Mu et al. 1994). Other genes encoding LRR-RPKs with known functions include the Arabidopsis BRI1 gene that functions in brassinosteroid signaling (Li and Chory 1997; Friedrichsen et al. 2000; He et al. 2000; Wang et al. 2001) and the rice $X a 21$ gene, which confers resistance to Xanthomonas oryzae $p v$. oryzae race 6 (Song et al. 1995).

EMS1 is required for specifying tapetal cell fate, and is needed for normal cytokinesis of microsporocytes. It is also involved in regulating the degeneration of the middle layer. Therefore, EMS1 has a function distinct from previously described LRR-RPKs. Our results support the idea that the EMS1 is a protein kinase that is localized to the cell membrane, further suggesting that EMS1 defines a new signaling pathway that controls the cell fate and patterning in anther development. Because the ems1 mutant phenotype suggests that the microsporocyte might be a default cell identity, it is possible that a signal from the microsporocytes is received by the EMS1 receptor, which then triggers the differentiation of tapetal cells. It will be very interesting to identify potential signals and substrates for the EMS1 protein to uncover components of this signaling pathway.

\section{Materials and methods}

Plant materials and mutant isolation

All Arabidopsis thaliana plants in this study are of the Landsberg erecta background. Plants were grown on soil with $16 \mathrm{~h}$ light $/ 8 \mathrm{~h}$ dark at $22^{\circ} \mathrm{C}$.

The generation of $D s$ insertional lines and screening of plants carrying $D s$ insertions were carried out as described /Sundaresan et al. 1995). Homozygous Ds plants were crossed with homozygous $A c$ plants (carrying an active transposase). The $D s /-A c /-$ double hemizygous F1 plants were grown to allow Ds transposition. F2 seedlings were then screened for plants carrying $D s$ insertions that segregated away from both the original $D s$ donor site and the $A c$ element. The mutants were screened from the F3 generation because most of them are hemizygous for the new Ds insertion at the F2 generation. To screen for revertant sectors, we crossed the ems1 mutant with an Ac-carrying plant. The F2 plants with a $D$ s excision could produce a revertant sector. We found that 11 of the F2 plants that exhibited mutant phenotypes produced large fertile revertant sectors. The putative revertant sectors were further confirmed by genetic and sequence analyses.

\section{Characterization of mutant phenotype}

Plants or flowers were photographed with a digital camera and a dissecting microscope. To observe live pollen grains, anthers prior to dehiscence were stained and photographed under a compound microscope (Alexander 1969). Fresh anthers were dissected and microspores were stained using Toluidine Blue $\mathrm{O}$ $(0.05 \%)$. Anther sections were stained by DAPI (4,6-diamino-2phenylindole dihydrochloride; Vector Laboratories). Examination of chromosomes in meiotic cells was performed as described (Ross et al. 1996).

For the anther structure study (Owen and Makaroff 1995), dissected floral buds and inflorescences were fixed in $2.8 \%$ (vol/ vol) glutaraldehyde in 0.1 M HEPES (N-2-Hydroxyethyl piperazine- $\mathrm{N}^{\prime}$-2-ethanesulfonic acid) buffer ( $\left.\mathrm{pH} 7.2\right)$ and $0.02 \%$ Triton $\mathrm{X}-100$ overnight at $4^{\circ} \mathrm{C}$. Samples were washed twice for $15 \mathrm{~min}$ each in $0.1 \mathrm{M}$ HEPES buffer (pH 7.2) and then fixed in $1 \%$ OsO4 overnight. They were then dehydrated in a graded acetone series (10\% increments) and embedded in Spurr's resin. Semi-thin $(0.5$ $\mu \mathrm{m})$ sections were made using an Ultracut E ultramicrotome (Reichert-Jung) and were stained with $0.25 \%$ of Toluidine Blue O. The images were photographed using an Optronics digital camera. Tapetal cells and microsporocytes were counted under the microscope from the central sections of the anther. Sections from ten individual buds were examined. In each bud, cell numbers were determined from four anthers, sixteen locules.

\section{Molecular analyses and in situ hybridizations}

Thermal asymmetric interlaced (TAIL)-PCR was performed with ems1 mutant genomic DNA and Ds3/AD2 or Ds5/AD4 primers (Liu et al. 1995; Grossniklaus et al. 1998). A portion of the EMS1 cDNA was amplified from a floral cDNA library (Dixit and Cyr 2002) with gene-specific primers oMC511: 5'TCGTCTCTTTTAAATCTCCGAGT-3' (beginning 48 nt upstream of the predicted ATG codon) and oMC512: 5'-AACATT TAAGGTTATATGGCTCAT-3' (the complement of the sequence including the stop codon and $20 \mathrm{nt}$ downstream). The PCR product was cloned into the pGEM $^{\circledR}$ - T vector (Promega) to yield the plasmid pMC2433.

RNA in situ hybridizations were performed on the wild-type and mutant floral sections essentially as described (Drews et al. 
1991; Flanagan and Ma 1994; Long and Barton 1998). Either radioactive probe or digoxigenin-labeled probe was used. For the EMS1 gene, a 1.2-kb cDNA fragment was amplified using primers oMC511 and oMC505, 5'-GGAATCGAACCACTTAAC AAG-3' and cloned into pGEM $^{\circledR}$-T vector, resulting in pMC2435. The ATA7 and SDS antisense and sense probes were synthesized using the pMC1577 (Rubinelli et al. 1998) and pMC2317 (Azumi et al. 2002) plasmids as templates, respectively.

\section{Kinase activity analysis}

A $0.95-\mathrm{kb}$ cDNA fragment encoding the kinase domain was PCR-amplified using primers oMC509: 5'-GTGATCCGATCA GAACCTGTATTTCTT-3' and oMC510: 5'-CGCTCGAGT TTAAGGTTATATGGCTCAT-3'. The PCR product was cloned into the pGEM $^{\circledR}$-T vector. The fragment was released by NotI and BamHI digestion and subcloned into the pYEX-4T-3 yeast expression vector (Skirpan et al. 2001) to produce pMC2438. After its sequence was confirmed, the pMC2438 construct was transformed into the $S$. cerevisae strain Y59 with selection for growth without uracil. Yeast cells were grown and the fusion protein was purified as described (Skirpan et al. 2001). Three micrograms of the fusion protein was incubated with 10 $\mu \mathrm{Ci}$ of $\left[\gamma^{-32} \mathrm{P}\right]$ ATP $\left(10^{5} \mathrm{cpm} / \mathrm{pmol}\right.$ ATP $)$ in kinase buffer $(50 \mathrm{mM}$ HEPES at pH7.4, $10 \mathrm{mM} \mathrm{MgCl}, 10 \mathrm{mM} \mathrm{MnCl} 2,1 \mathrm{mM} \mathrm{DTT}$ ) for $1 \mathrm{~h}$ at room temperature. The reaction was terminated by adding $1 / 2$ volume of SDS-PAGE sample buffer, incubated for $3 \mathrm{~min}$ at $95^{\circ} \mathrm{C}$, and the phosphorylated proteins were separated by $12 \%$ SDS-PAGE.

\section{EMS1 localization analysis}

To reduce the chance of PCR-induced mutations and for the ease of cloning, a portion of EMS1 cDNAs was amplified rather than the entire coding region. A $0.65-\mathrm{kb}$ cDNA encoding transmembrane domain and partial kinase domain was PCR-amplified by using primers oMC637: 5'-ACCCATGGGTGTTTG TCAGGATCC- ${ }^{\prime}$ ' and oMC638: 5'-ACCCATGGTCCCAGT TTGGTTCCT-3'. The PCR product was cloned into the pGEM $^{\circledR}-\mathrm{T}$ vector and was released by $\mathrm{NcoI}$ digestion. This fragment was subcloned into the sGFP vector containing the $35 \mathrm{~S}$ promoter and a synthetic GFP sequence (Chiu et al. 1996) to produce pMC2573. Then, $2.5 \mu \mathrm{g}$ of the pMC2573 plasmid and sGFP vectors were used to coat gold particles and divided into three aliquots. The onion epidermis was peeled and bombarded by using a gene gun (Model PDS-100/He Biolistik ${ }^{\circledR}$ Particle Delivery System, Bio-Rad). The bombarded samples were incubated at $22^{\circ} \mathrm{C}$ for $24 \mathrm{~h}$ on an MS plate with $3 \%$ agar. Cells with GFP fluorescence were observed using an Olympus FV300 laser scanning confocal microscope (Olympus America). The GFP was excited using a 488-nm argon laser with emitting light filtered though $510 \mathrm{~nm}$ IFLP and 530 IFSP filters.

\section{Acknowledgments}

We thank R. Walsh and K. Glyde for preparation of anther sections, W. Li for helping with DAPI staining of microsporocytes, and T.-H. Kao and A.L. Skirpan for advice on the analysis of protein kinase activity. We thank L. Ding for providing the sGFP vector and assisting with the particle bombardment experiment, M. Guiltinan and S. Maximova for the use of the gene gun, E. Kunze for confocal microscope imaging, and A. Omeis for plant care. We also thank J. Chory, C. Makaroff, Z.-Y. Wang, Z. Yang, A. Marcus, and R. Pilloff for valuable comments on our manuscript. This work was supported by NSF, USDA, and NIH grants (H.M.) and funds from the Department of Biology and the Life Sciences Consortium at Pennsylvania State University.

The publication costs of this article were defrayed in part by payment of page charges. This article must therefore be hereby marked "advertisement" in accordance with 18 USC section 1734 solely to indicate this fact.

\section{References}

Alexander, M.P. 1969. Differential staining of aborted and nonaborted pollen. Stain Technol. 44: 117-122.

Azumi, Y., Liu, D., Zhao, D.Z., Li, W., Wang, G.F., Hu, Y., and $\mathrm{Ma}, \mathrm{H}$. 2002. Homolog interaction during meiotic prophase I in Arabidopsis requires the SOLO DANCERS gene encoding a novel cyclin-like protein. EMBO J. 21: 3081-3095.

Balasubramanian, S. and Schneitz, K. 2000. NOZZLE regulates proximal-distal pattern formation, cell proliferation and early sporogenesis during ovule development in Arabidopsis thaliana. Development 127: 4227-4238.

Becraft, P.W. 1998. Receptor kinases in plant development. Trends in Plant Sci. 3: 384-388.

Bowman, J.L., Smyth, D.R., and Meyerowitz, E.M. 1989. Genes directing flower development in Arabidopsis. Plant Cell 1: $37-52$.

Chaudhury, A.M., Lavithis, M., Taylor, P.E., Craig, S., Singh, M.B., Signer, E.R., Knox, R.B., and Dennis, E.S. 1994. Genetic control of male fertility in Arabidopsis thaliana: Structural analysis of premeiotic developmental mutants. Sex. Plant Reprod. 7: 17-28.

Chiu, W., Niwa, Y., Zeng, W., Hirano, T., Kobayashi, H., and Sheen, J. 1996. Engineered GFP as a vital reporter in plants. Curr. Biol. 6: 325-330.

Clark, S.E., Jacobsen, S.E., Levin, J.Z., and Meyerowitz, E.M. 1996. The CLAVATA and SHOOT MERISTEMLESS loci competitively regulate meristem activity in Arabidopsis. Development 122: 1567-1575.

Clark, S.E., Williams, R.W., and Meyerowitz, E.M. 1997. The CLAVATA1 gene encodes a putative receptor kinase that controls shoot and floral meristem size in Arabidopsis. Cell 89: $575-585$

Coen, E.S. and Meyerowitz, E.M. 1991. The war of the whorls: Genetic interactions controlling flower development. $\mathrm{Na}$ ture 353: 31-37.

Dawson, J., Wilson, Z.A., Aarts, M.G.M., Braithwaite, A.F., Briarty, L.G., and Mulligan, B.J. 1993. Microspore and pollen development in six male-sterile mutants of Arabidopsis thaliana. Can. J. Bot. 71: 629-638.

Denis, M., Delourme, R., Gourret, J.P., Mariani, C., and Renard, M. 1993. Expression of engineered nuclear male sterility in Brassica napus. Plant Physiol. 101: 1295-1304.

Dixit, R. and Cyr, R.J. 2002. Golgi secretion is not required for marking the preprophase band site in cultured tobacco cells. Plant J. 29: 99-108.

Drews, G.N., Bowman, J.L., and Meyerowitz, E.M. 1991. Negative regulation of the Arabidopsis homeotic gene AGAMOUS by the APETALA2 product. Cell 65: 991-1002.

Flanagan, C.A. and Ma, H. 1994. Spatially and temporally regulated expression of the MADS-box gene AGL2 in wild-type and mutant Arabidopsis flowers. Plant Mol. Biol. 26: 581595.

Friedrichsen, D.M., Joazeiro, C.A., Li, J., Hunter, T., and Chory, J. 2000. Brassinosteroid-insensitive-1 is a ubiquitously expressed leucine-rich repeat receptor serine/threonine kinase. Plant Physiol. 123: 1247-1256. 
Goldberg, R.B., Beals, T.P., and Sanders, P.M. 1993. Anther development: Basic principles and practical applications. Plant Cell 5: 1217-1229.

Gori, P. 1982. Accumulation of polysaccharides in the anther cavity of Allium sativum, clone Piemonte. J. Ultrastruct. Res. 81: 158-162.

Goto, K. and Meyerowitz, E.M. 1994. Function and regulation of the Arabidopsis floral homeotic gene PISTILLATA. Genes \& Dev. 8: 1548-1560.

Grossniklaus, U., Vielle-Calzada, J.P., Hoeppner, M.A., and Gagliano, W.B. 1998. Maternal control of embryogenesis by $M E D E A$, a polycomb group gene in Arabidopsis. Science 280: 446-450.

He, Z., Wang, Z.Y., Li, J., Zhu, Q., Lamb, C., Ronald, P., and Chory, J. 2000. Perception of brassinosteroids by the extracellular domain of the receptor kinase BRI1. Science 288: 2360-2363.

Izhar, S. and Frankel, R. 1971. Mechanism of male sterility in Petunia: The relationship between $\mathrm{pH}$, callase activity in the anthers, and the breakdown of the microsporogenesis. Theor. Appl. Genet. 44: 104-108.

Jack, T., Brockman, L.L., and Meyerowitz, E.M. 1992. The homeotic gene APETALA3 of Arabidopsis thaliana encodes a MADS box and is expressed in petals and stamens. Cell 68: 683-697.

Jinn, T.L., Stone, J.M., and Walker, J.C. 2000. HAESA, an Arabidopsis leucine-rich repeat receptor kinase, controls floral organ abscission. Genes \& Dev. 14: 108-117.

Li, J. and Chory, J. 1997. A putative leucine-rich repeat receptor kinase involved in brassinosteroid signal transduction. Cell 90: 929-938.

Liu, Y., Mitsukawa, N., Oosumi, T., and Whitier, R.F. 1995. Efficient isolation and mapping of Arabidopsis thaliana TDNA insert junctions by thermal asymmetric interlaced PCR. Plant J. 8: 457-463.

Long, J.A. and Barton, M.K. 1998. The development of apical embryonic pattern in Arabidopsis. Development 125: 30273035.

Ma, H. 1994. The unfolding drama of flower development: Recent results from genetic and molecular analyses. Genes \& Dev. 8: 745-756.

Ma, H. and dePamphilis, C. 2000. The ABCs of floral evolution. Cell 101: 5-8.

Mariani, C., Beuckeleer, M.D., Truettner, J., Leemans, J., and Goldberg, R.B. 1990. Induction of male sterility in plants by a chimaeric ribonuclease gene. Nature 347: 737-741.

- 1992. A chimaeric ribonuclease-inhibitor gene restores fertility to male sterile plants. Nature 357: 384-387.

McCarty, D.R. and Chory, J. 2000. Conservation and innovation in plant signaling pathways. Cell 103: 201-209.

McCormick, S. 1993. Male gametophyte development. Plant Cell 5: 1265-1275.

Mepham, R.M. 1970. Development of pollen grain wall: Further work with Tradescantia bracteata. Protoplasma 68: 39-54.

Meyerowitz, E.M., Bowman, J.L., Brockman, L.L., Drews, G.N., Jack, T., Sieburth, L.E., and Weigel, D. 1991. A genetic and molecular model for flower development in Arabidopsis thaliana. Dev. Suppl. 1: 157-167.

$\mathrm{Mu}$, J.H., Lee, H.S., and Kao, T.-h. 1994. Characterization of a pollen-expressed receptor-like kinase gene of Petunia inflata and the activity of its encoded kinase. Plant Cell 6: 709-721.

Owen, H.A. and Makaroff, C.A. 1995. Ultrastructure of microsporogenesis and microgametogenesis in Arabidopsis thaliana (L.) Heynh. ecotype Wassilewskija (Brassicaceae). Protoplasma 185: 7-21.
Pacini, E. and Juniper, B.E. 1983. The ultrastructure of formatiom and development of the amoebiod tapetum in Arum italicum Miller. Protoplasma 117: 116-129.

Pacini, E., Franchi, G.G., and Hesse, M. 1985. The tapetum: Its form, function, and possible phylogeny in Embryophyta. Plant Systematics and Evolution 149: 155-185.

Pelaz, S., Ditta, G.S., Baumann, E., Wisman, E., and Yanofsky, M.F. 2000. B and C floral organ identity functions require SEPALLATA MADS-box genes. Nature 405: 200-203.

Ross, K.J., Fransz, P., and Jones, G.H. 1996. A light microscopic atlas of meiosis in Arabidopsis thaliana. Chromosome Res. 4: 507-516.

Rubinelli, P., Hu, Y., and Ma, H. 1998. Identification, sequence analysis and expression studies of novel anther-specific genes of Arabidopsis thaliana. Plant Mol. Biol. 37: 607-619.

Sanders, P.M., Anhthu, Q.B., Weterings, K., McIntire, K.N., Hsu, Y., Lee, P.Y., Troung, M.T., Beals, T.P., and Goldberg, R.B. 1999. Anther developmental defects in Arabidopsis thaliana male-sterile mutants. Sex. Plant Reprod. 11: 297322.

Schenk, P.W. and Snaar-Jagalska, B.E. 1999. Signal perception and transduction: The role of protein kinases. Biochim. Biophys. Acta 1449: 1-24.

Schiefthaler, U., Balasubramanian, S., Sieber, P., Chevalier, D., Wisman, E., and Schneitz, K. 1999. Molecular analysis of NOZZLE, a gene involved in pattern formation and early sporogenesis during sex organ development in Arabidopsis thaliana. Proc. Natl. Acad. Sci. 96: 11664-11669.

Scott, R., Hodge, R., Paul, W., and Draper, J. 1991. The molecular biology of anther differentiation. Plant Sci. 80: 167-191.

Shiu, S.H. and Bleecker, A.B. 2001. Receptor-like kinases from Arabidopsis form a monophyletic gene family related to animal receptor kinases. Proc. Natl. Acad. Sci. 98: 1076310768.

Skirpan, A.L., McCubbin, A.G., Ishimizu, T., Wang, X., Hu, Y., Dowd, P.E., Ma, H., and Kao, T.-h. 2001. Isolation and characterization of kinase interacting protein 1 , a pollen protein that interacts with the kinase domain of PRK1, a receptorlike kinase of petunia. Plant Physiol. 126: 1480-1492.

Song, W.Y., Wang, G.L., Chen, L.L., Kim, H.S., Pi, L.Y., Holsten, T., Gardner, J., Wang, B., Zhai, W.X., Zhu, L.H., et al. 1995. A receptor kinase-like protein encoded by the rice disease resistance gene, Xa21. Science 270: 1804-1806.

Stieglitz, H. 1977. Role of $\beta$-1,3-glucan in postmeiotic microspore release. Dev. Biol. 57: 87-97.

Stone, J.M. and Walker, J.C. 1995. Plant protein kinase families and signal transduction. Plant Physiol. 108: 451-457.

Sundaresan, V., Springer, P., Volpe, T., Haward, S., Jones, J.D., Dean, C., Ma, H., and Martienssen, R. 1995. Patterns of gene action in plant development revealed by enhancer trap and gene trap transposable elements. Genes \& Dev. 9: 1797-1810.

Takegami, M.H., Yoshioka, M., Tanaka, I., and Ito, M. 1981. Characteristics of isolated microsporocytes from liliaceous plants for studies of the meiotic cell cycle in vitro. Plant Cell Physiol. 22: 1-10.

Taylor, P.E., Glover, J.A., Lavithis, M., Craig, S., Singh, M.B., Knox, R.B., Dennis, E.S., and Chaudhury, A.M. 1998. Genetic control of male fertility in Arabidopsis thaliana: Structural analyses of postmeiotic developmental mutants. Planta 205: 492-505.

Torii, K.U., Mitsukawa, N., Oosumi, T., Matsuura, Y., Yokoyama, R., Whittier, R.F., and Komeda, Y. 1996. The Arabidopsis ERECTA gene encodes a putative receptor protein kinase with extracellular leucine-rich repeats. Plant Cell 
8: 735-746.

Walker, J.C. 1994. Structure and function of the receptor-like protein kinases of higher plants. Plant Mol. Biol. 26: 15991609.

Wang, Z.Y., Seto, H., Fujioka, S., Yoshida, S., and Chory, J. 2001. BRI1 is a critical component of a plasma-membrane receptor for plant steroids. Nature 410: 380-383.

Weigel, D. 1995. The genetics of flower development: From floral induction to ovule morphogenesis. Annu. Rev. Genet. 29: 19-39.

Wilson, Z.A., Morroll, S.M., Dawson, J., Swarup, R., and Tighe, P.J. 2001. The Arabidopsis MALE STERILITY1 (MS1) gene is a transcriptional regulator of male gametogenesis, with homology to the PHD-finger family of transcription factors. Plant J. 28: 27-39.

Yang, W.C., Ye, D., Xu, J., and Sundaresan, V. 1999. The SPOROCYTELESS gene of Arabidopsis is required for initiation of sporogenesis and encodes a novel nuclear protein. Genes \& Dev. 13: 2108-2117.

Yanofsky, M.F., Ma, H., Bowman, J.L., Drews, G.N., Feldmann, K.A., and Meyerowitz, E.M. 1990. The protein encoded by the Arabidopsis homeotic gene agamous resembles transcription factors. Nature 346: 35-39. 


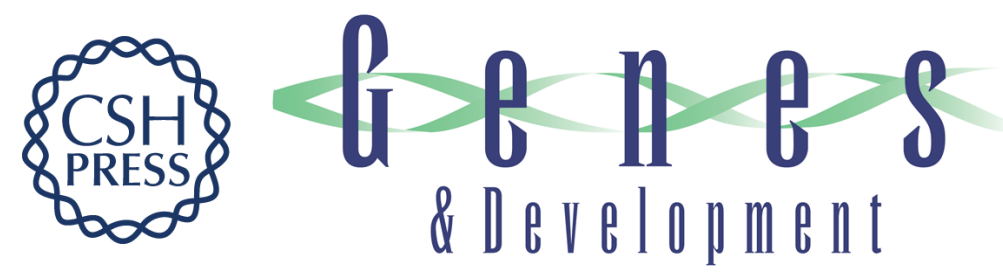

\section{The EXCESS MICROSPOROCYTES1 gene encodes a putative leucine-rich repeat receptor protein kinase that controls somatic and reproductive cell fates in the Arabidopsis anther}

Da-Zhong Zhao, Guan-Fang Wang, Brooke Speal, et al.

Genes Dev. 2002, 16:

Access the most recent version at doi:10.1101/gad.997902

References This article cites 61 articles, 23 of which can be accessed free at:

http://genesdev.cshlp.org/content/16/15/2021.full.html\#ref-list-1

License

Email Alerting Receive free email alerts when new articles cite this article - sign up in the box at the top

Service right corner of the article or click here.

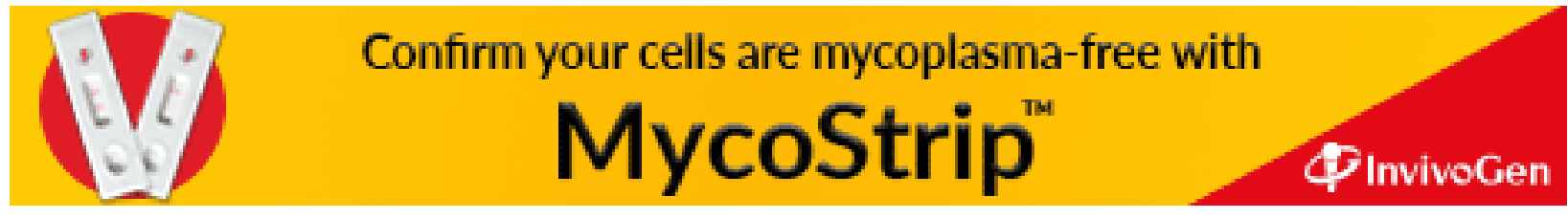

